\title{
Durability Studies on Fiber-Reinforced Siderurgic Concrete
}

\section{Vanesa Ortega-López ${ }^{1}$, Víctor Revilla-Cuesta ${ }^{2}$, Amaia Santamaría $^{3}$, Ana B. Espinosa ${ }^{4}$, José A. Fuente-Alonso ${ }^{5}$ and José A. Chica ${ }^{6}$}

\author{
${ }^{1}$ University of Burgos. Escuela Politécnica Superior, 09001 Burgos, Spain. vortega@ubu.es \\ ${ }^{2}$ University of Burgos. Escuela Politécnica Superior, 09001 Burgos, Spain. vrevilla@ubu.es \\ ${ }^{3}$ University of Basque Country. Escuela de Ingeniería de Bilbao, 48013 Bilbao, Spain. \\ amaia.santamaria@ehu.es \\ ${ }^{4}$ University of Burgos. Escuela Politécnica Superior, 09001 Burgos, Spain. aespinosa@ubu.es \\ ${ }^{5}$ University of Burgos. Escuela Politécnica Superior, 09001 Burgos, Spain. jafuente@ubu.es \\ ${ }^{6}$ Fundación Tecnalia, Research \& Innovation. Digital Construction Division, 48160 Derio, Vizcaya, \\ Spain.joseantonio.chica@tecnalia.com
}

\begin{abstract}
The construction sector is clearly one of the most pollutant at a global level and its consumption of natural resources is also enormous. Over recent years, heightened awareness of this issue within the construction sector has motivated changes within its working practice, seeking to reduce its environmental impacts and to mitigate the effects of climate change. The consumption of natural resources can be reduced in very different areas and special attention has been given to the substitution of Natural Aggregates (NA) in concrete design by replacing those aggregates with various waste coproducts. Siderurgic concrete is the name given to concrete manufactured with siderurgical aggregate from the steel-making industry. In this paper, test results on fiber-reinforced siderurgical concrete are reported. The concrete is manufactured with approximately 50\% Electric Arc Furnace Slag (EAFS) aggregate by volume, for use in pavement applications. Steel and polypropylene fibers, amounting to approximately $0.5 \%$ by volume of the concrete mass, are also added to the mix. The durability properties of this concrete type are analyzed through freeze/thaw and moist/dry tests. Furthermore, the long-term behavior of the concrete is explained through its internal structure, using Mercury Intrusion Porosity (MIP) and low-vacuum Scanning Electron Microscopy (SEM) analyses. The results add further weight to the feasibility of using EAFS in replacement of NA in fiber-reinforced concrete for pavement construction.
\end{abstract}

Keywords: EAFS, Freeze/Thaw, Moist/Dry, MIP, SEM.

\section{Introduction}

The immense volumes of natural aggregates used for concrete production within the construction sector has motivated a search for feasible alternatives to natural resources. In consequence, several studies have over the past few decades examined the incorporation of slag from the steelmaking industry in construction and civil engineering applications (Akinmusuru, 1991; Faleschini et al., 2015; Geiseler, 1996; Koros, 2003; Manso et al., 2006; Motz and Geiseler, 2001; Pellegrino and Gaddo, 2009; Qasrawi, 2014; Santamaría et al., 2017).

Although productive steel processes differ between plants, they may at present be divided into two types: Integral Siderurgy, in which the raw material, iron ore, is melted in a Blast Furnace, followed by a decarburization phase, usually in an Oxygen-Blow Converter, and the 
Electric Cycle, in which scrap is melted in Electric Arc Furnaces (EAF). After this "primary metallurgy", a secondary refining phase usually takes place in a Ladle Furnace for carbon steels, and in a special converter for stainless steels.

Around 30\% of European steel is produced with EAF technology. In the EU steel sector, a total of 47.8 Mt of steel slag were produced in 2018, of which Electric Arc Furnace Slag (EAFS) and secondary slags amounted to $7.9 \mathrm{Mt}$ and $2.8 \mathrm{Mt}$, respectively, according to the EUROSLAG report "The European Association representing metallurgical slag producers and processors" (EUROSLAG, 2018), data from which are reproduced in Figure 1.
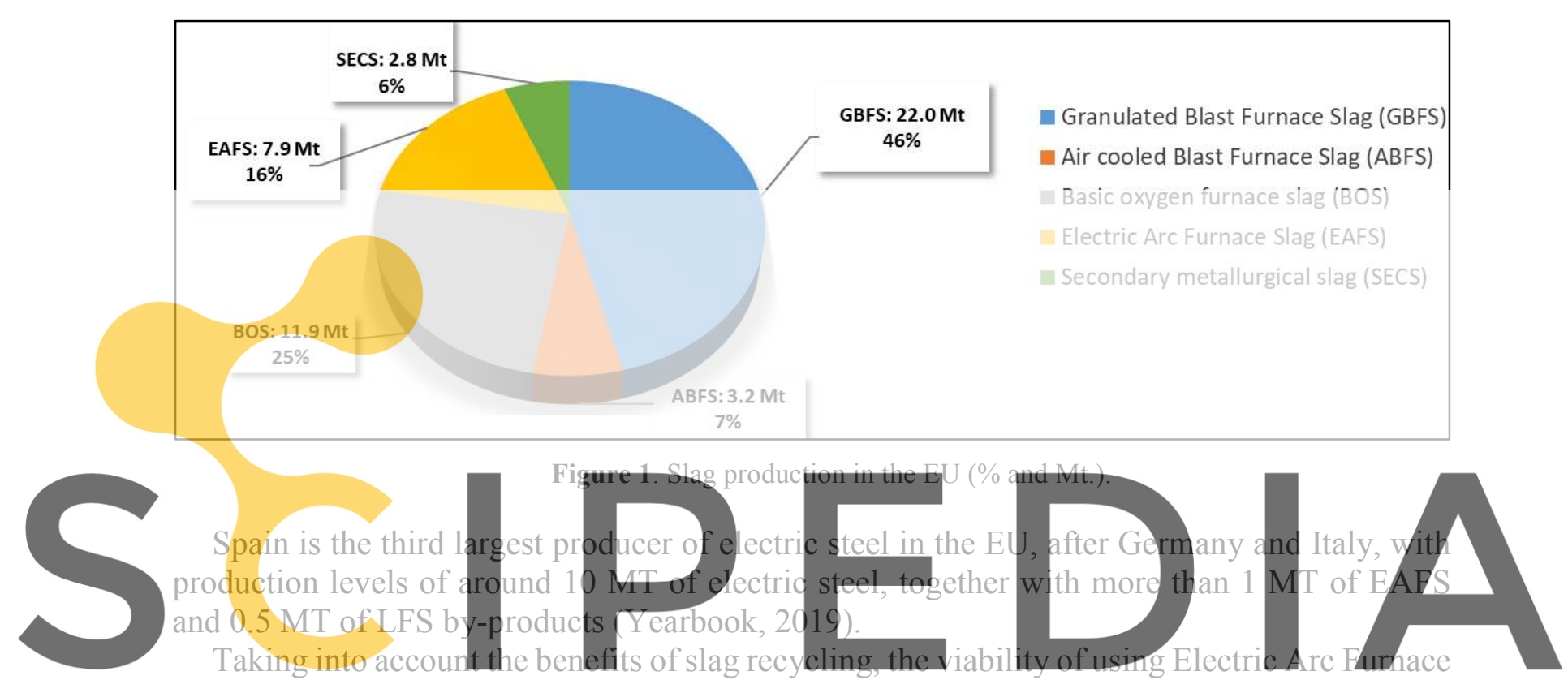

Slags (EAFS) in fiber-reinforced concrete (FRC) is examined in this paper, for the subsequent

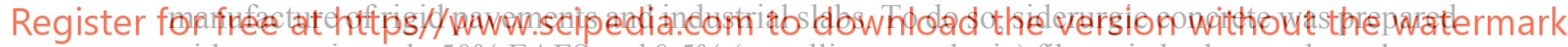

with approximately 50\% EAFS and 0.5\% (metallic or synthetic) fibers, in both cases by volume.

The main mechanical properties of these siderurgic concretes will be analyzed and their longterm behavior examined in relation to their internal structure in the following sections, leading up to a discussion of the most significant results and relevant conclusions.

\section{Materials and Methodology}

The materials used in this research were: Ordinary Portland Cement (OPC) CEM I 42,5R, water, natural siliceous aggregates provided in three granulometric sizes of $0 / 4,4 / 12$ and 12/25 $\mathrm{mm}$, superplasticizers (polycarboxylate modified with water), EAFS aggregates provided in three granulometric sizes of 0/4, 4/10 and 10/20 mm, metallic fibers (steel, RL-45/50-BN) and synthetic Fibers (polypropylene, M-48).

The main physical characteristics of the EAFS were: specific gravity of $3500 \mathrm{~kg} / \mathrm{m}^{3}$, high water absorption, low fines content, and $24 \%$ Los Angeles abrasion loss. The main chemical components were oxides of $\mathrm{Fe}, \mathrm{Ca}$ and $\mathrm{Si}$. 
The methodology was based on the use of EAFS as coarse and medium aggregate in the concrete mix and the fine aggregate was prepared with 50\% fine slag and 50\% siliceous sand, in order to compensate for the lack of the fines in the EAFS.

Two reference mixtures were designed: mixture $P$, manufactured entirely with siliceous aggregates, and mixture E, manufactured with EAFS in coarse and medium gravel and 50\%$50 \%$ of siliceous-EAFS in sand. Their mix design is shown in Table 1.

Taking the dosage of mixture $\mathrm{E}$ as a reference, two experimental mixtures reinforced with around $0.5 \%$ by volume of steel fibers identified as EM and with polypropylene fibers identified as ES were manufactured.

Table 1. Mix design of the reference mixtures $\left(\mathrm{kg} / \mathrm{m}^{3}\right)$.

\begin{tabular}{cccccccccc}
\hline \multirow{2}{*}{ Mix design $\mathrm{kg} / \mathrm{m}^{3}$} & \multirow{2}{*}{ Cement } & \multirow{2}{*}{ Water } & \multicolumn{6}{c}{ Siliceous aggregates } & \multicolumn{3}{c}{ EAFS aggregates } & \multirow{2}{*}{ Admixture } \\
\cline { 4 - 9 } & & $0 / 4$ & $4 / 12$ & $12 / 20$ & $0 / 4$ & $4 / 10$ & $10 / 20$ & \\
\hline $\mathrm{P}$ & 360 & 180 & 800 & 575 & 465 & - & - & - & 3.63 \\
$\mathrm{E}$ & 360 & 180 & 500 & - & - & 515 & 670 & 550 & 5.44 \\
\hline
\end{tabular}

\section{Results and Discussion}

\subsection{Mechanical Properties}

The main mechanical properties of the siderurgic concretes are shown in Table 2

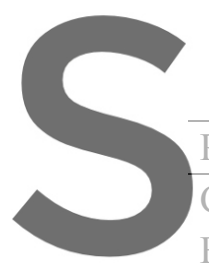

Table 2. Mechanical properties of the
Property
Compressive Strength at 28 days $(\mathrm{MIPa})$
Flexural Strength at 28 days $(\mathrm{MPa})$

Splitting Tensile Strength at 28 days $(\mathrm{MPa})$

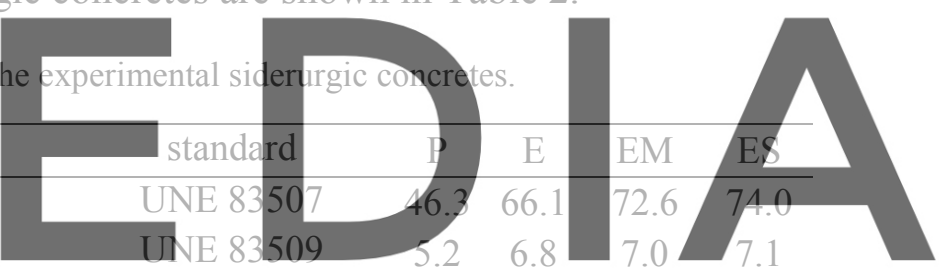

UNE 12390-6

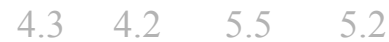

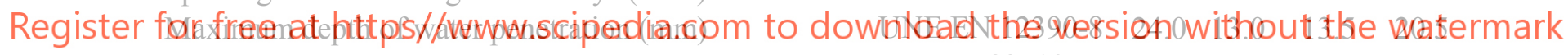

Flexural toughness $(\mathrm{N} \cdot \mathrm{m})$

LOP $(\mathrm{CMOD} \leq 0.05 \mathrm{~mm})(\mathrm{MPa})$

UNE 83510

EN-14651

Blows until breakage in impact strength test

UNE 83514

$6.16 .4 \quad 6.2$

The compressive strength of the siderurgic concrete E (66.1 MPa) was $43 \%$ higher than that of natural aggregates $\mathrm{P}(46.3 \mathrm{MPa})$, even reaching values of 72 and $74 \mathrm{MPa}$ for mixtures $\mathrm{EM}$ and ES, respectively.

The flexural strength of the siderurgic concrete $\mathrm{E}(6.8 \mathrm{MPa})$ was also higher than that of conventional concrete P (5.2 MPa); mixtures EM and ES reaching values of around $7 \mathrm{MPa}$. This fact is attributable to the good (dense and not very porous) quality of the Interfacial Transition Zone (ITZ) of the siderurgic concretes (Arribas et al., 2015) and to high adhesion between all the (aggregate, cement paste and fiber) components of the mixtures.

As regards the splitting tensile strength, little difference was observed between the reference concretes $\mathrm{P}$ (4.3 MPa, with fibers) and $\mathrm{E}$ (4.2 $\mathrm{MPa}$, no fibers). An important improvement in the mixtures with fibers was once again observed, especially concretes EM (5.5 MPa) and ES $(5.2 \mathrm{MPa})$. 
All the mixes with EAFS showed better resistance to water penetration than the conventional concrete with natural aggregates. Likewise, they met the requirements of the EHE standard (2008), which specifies the maximum depth of water penetration under $30 \mathrm{~mm}$. The impermeable nature of these concretes was therefore considered sufficient for pavement applications.

The toughness by flexion value of the fiber-reinforced mixes was close to $40 \mathrm{~N} . \mathrm{mm}$ in the mix with steel fibers and was slightly lower in the mix with polypropylene fibers (35 N.mm), which in both cases are good values.

The Limit of Proportionality (LOP) tested in samples with a notch of $5 \mathrm{~mm}$ was similar in all the mixtures and was slightly higher in the mixtures with steel fibers $(6.4 \mathrm{MPa})$.

Finally, the fiber-reinforced siderurgic concretes clearly had much a better impact strength until breakage (EM: 155 blows and ES: 88 blows) than the equivalent with non-reinforced concrete $\mathrm{E}$ (13 hits).

In view of these initial results, it can be concluded that the siderurgic concretes have the mechanical properties that are needed in industrial pavement slabs.

\subsection{Long-Term Behavior and Durability}

\subsubsection{Freeze/thaw and moist/dry tests}

The durability of a concrete pavement is determined by its permeability and its resistance to the very influential factors, such as the presence of water and temperature variance in its immediate environment. The freeze/thaw and moist/dry tests of the concretes ynder are especially
interesting, given the very adverse climatic conditions of the Spanish region under study.
In this study, both the weight and the compressive strength of the mixes varied, folloying
56 freeze/thaw cycles and 30 moist/dry cycles, as per the UNE-CEN/TS 12390-9 and the ASTM
D-559 standards("Annual Book of ASTM Standars, ASTM International, West Conshohocken, 19429-2959. PA, USA, 2008,"), respectively. The results are shown below, in Table 3.

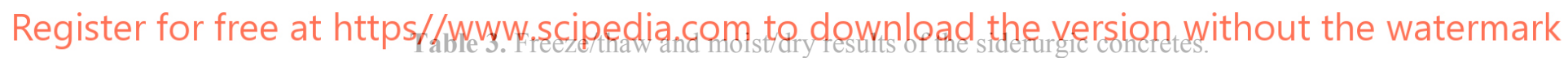

\begin{tabular}{lccc}
\hline Property & E & EMI & ES \\
\hline Weight variation after 56 freeze/thaw cycles (\%) & -62.41 & -2.92 & -4.49 \\
\hline Variation of compressive strength after 56 freeze/thaw cycles (\%) & - & -3.45 & 0.93 \\
\hline Weight variation after 30 moist/dry cycles (\%) & 0.23 & 0.14 & 0.34 \\
\hline Variation of compressive strength after 30 moist/dry cycles (\%) & -15.2 & -1.12 & 12.16 \\
\hline
\end{tabular}

In the freeze/thaw test, cubic specimens, in duplicate, were introduced into a container filled with a solution of $3 \%$ sodium chloride $(\mathrm{NaCl})$. These containers were placed in a freezer over 16 hours, at a temperature of $-29^{\circ} \mathrm{C} \pm 1^{\circ} \mathrm{C}$, and in a container with water circulation at $20^{\circ} \mathrm{C} \pm 1^{\circ} \mathrm{C}$ for 8 hours, and those test cycles were repeated 56 times throughout the duration of the test. Figure 2 shows the arrangement of the freeze/thaw test. 


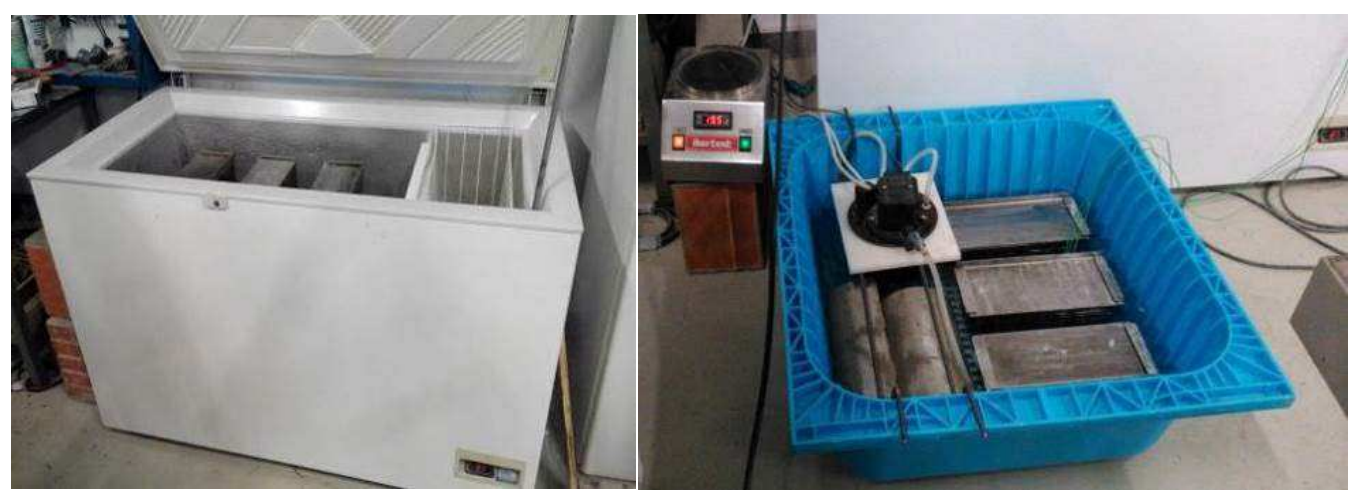

Figure 2. Arrangement of the freeze/thaw test: a) freezer at $-29^{\circ} \mathrm{C}$; b) container with water at $20^{\circ} \mathrm{C}$.

After 56 freeze/thaw cycles, mix E lost a significant amount of material (-62.41\%), while the results obtained for concrete mix ES $(-4.49 \%)$ were good and even better for concrete mix EM (-2.92\%), which maintained its cube shape. The compressive strength test at the end of all the cycles was only performed on the EM and ES specimens, due to the total deterioration of the E specimens during the freeze/thaw test. Slight damage to the EM specimens led to a decrease of $3.45 \%$ in their compressive strength, while the ES specimen showed a compressive strength that was slightly higher $(+0.93 \%)$ than before the freeze/thaw cycles. A fact also observed by other authors, which was probably caused by further hydration of the cement that came into direct contact with the water permeating through the frozen saturated surface due to

its microporosity (Pelle

The moist/dry test was

cycles, repeated 30 tim

temperature and 8 hours

After the moist/dry test,
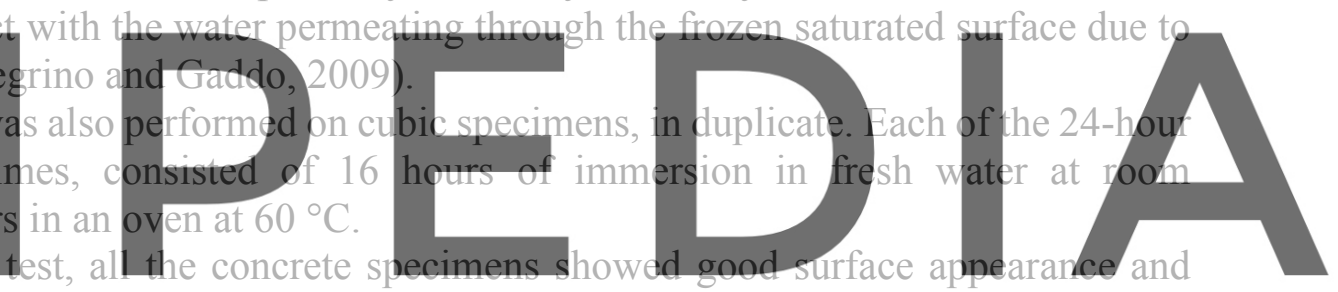

slight weight gains. The concrete with no fibers, E, showed an appreciable loss of compressive

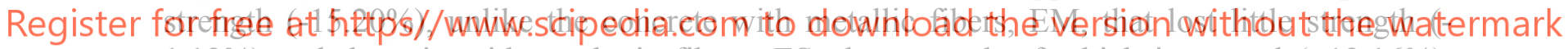
$1.12 \%)$ and the mix with synthetic fibers, ES, the strength of which increased $(+12.16 \%)$. Similar results for concretes manufactured with EAFS were also found by other authors (Arribas et al., 2014). These satisfactory results point to the good internal cohesiveness of the aggregates and fibers within the matrix of this fiber-reinforced slag concrete.

\subsubsection{MIP analysis}

Concrete-matrix porosity is a determining factor, in both the mechanical properties and the durability of cement-based materials, and was measured with Mercury Intrusion Porosimetry (MIP) analysis. The porosity values were as follows: $12.3 \%$ for mix E; $10.3 \%$ for mix EM; and, $11.5 \%$ for mix ES; common values for well-performed concretes (Ortega-López et al., 2018).

The lower porosity of the fiber-reinforced concretes with respect to the mix E, means that both the EM and the ES mixes were more compacted, which may also explain their higher compressive strength and the lower weight variation after the freeze/thaw and the moist/dry tests. The pore size frequency, shown in Figure 3, rises to an significant peak at around $100 \mathrm{~nm}$, 
higher in concrete E, with no fibers, which could be one cause of the worse behavior of this concrete against physical and chemical agents.

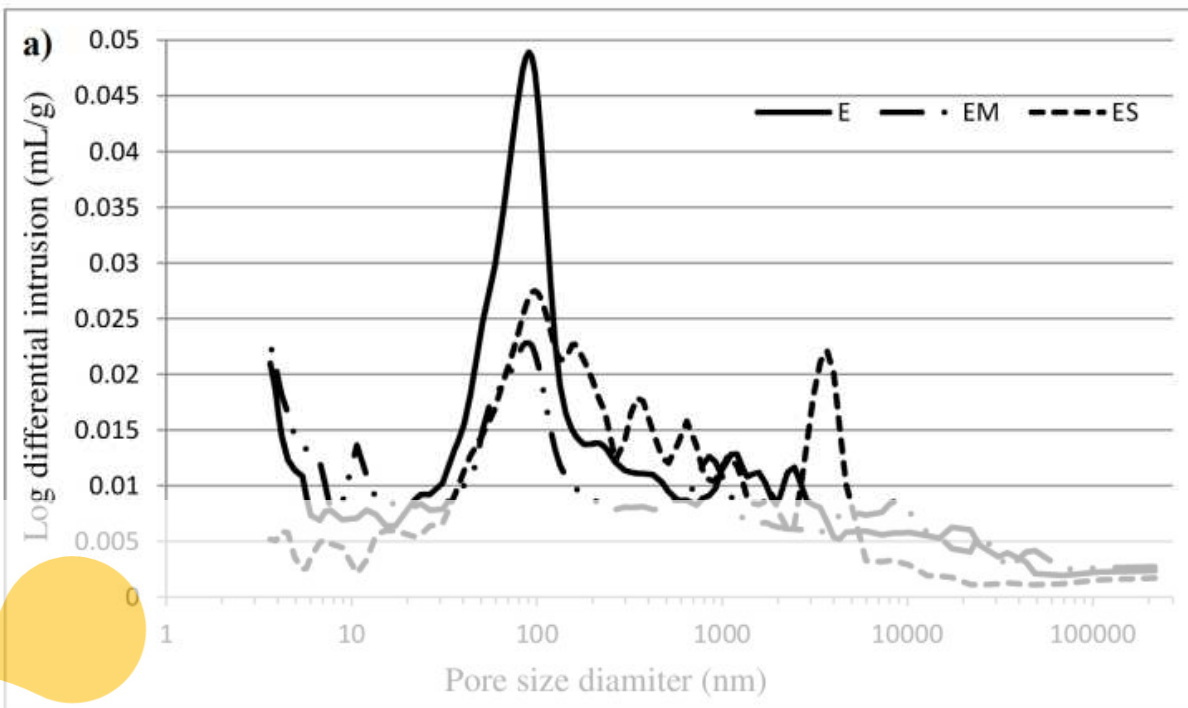

Figure 3. MIP analysis of siderurgic concretes: differential intrusion.

\subsubsection{SEM observations}

Low-vacuum scanning was used for analyzing

between the concrete co

Figure 4 shows three SEM images, one of each siderurgic

images, it can be observed that the EAFS pat
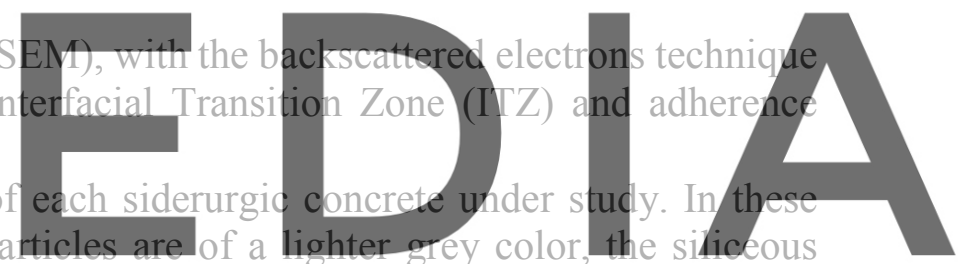

particles are darker grey and, Figure $4 \mathrm{~b}$ and Figure $4 \mathrm{c}$ clearly show the fibers, steel and

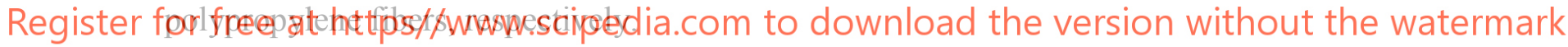
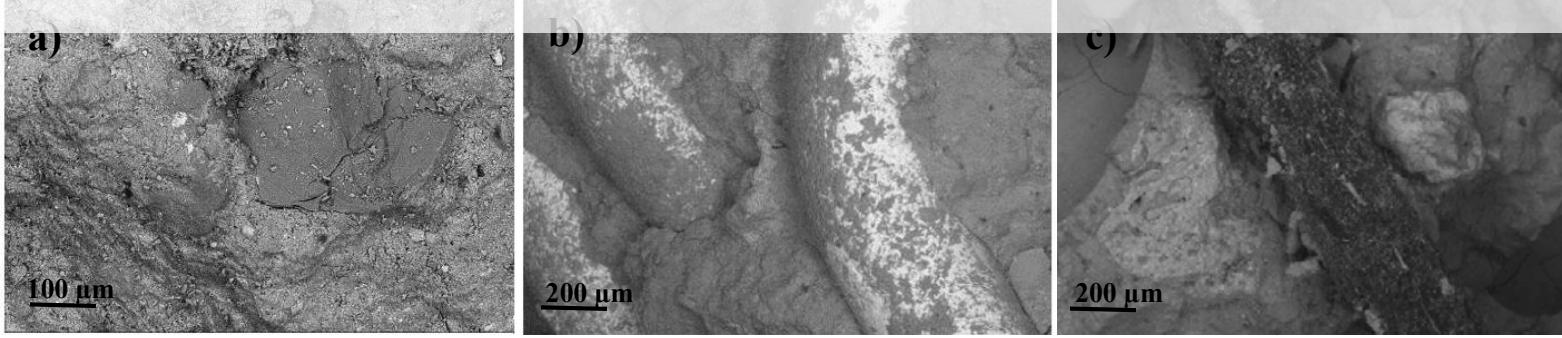

Figure 4. SEM images of concretes: a) concrete E; b) concrete EM; c) concrete ES.

All the SEM images support the conclusion that the cementitious matrices are of good quality, with excellent adherence of aggregates and fibers, which favors the durability of these concretes. 


\section{Conclusions}

The conclusions of this work can be summarized as follows:

- The fiber-reinforced siderurgic concrete mixtures showed good mechanical properties. The results of the concretes reinforced with steel fibers were in general better than those for the concretes reinforced with polypropylene fibers.

- Durability tests delivered good results for the fiber-reinforced siderurgic concretes, yielding smaller variations of weight and strength after several conditions.

- MIP and SEM analyses revealed the good internal cohesiveness of both aggregates and fibers within the cement matrix, which favored their durability.

\section{Acknowledgements}

The authors wish to express their gratitude to: the Spanish Ministry MCIU, AEI, EU and ERDF [RTI2018-097079B-C31; 10.13039/501100011033; FPU17/03374]; the Junta de Castilla y León (Regional Government) and ERDF [UIC-231, BU119P17]; Youth Employment Initiative (JCyL) and ESF [UBU05B_1274]; and finally, the funds from the university of The Basque Country [PPGA19/61] and the university of Burgos [grant SUCONS; Y135.GI]. Additionally, our thanks to the Basque Government research group [IT1314-19] and likewise to CHRYSO and HORMOR for supplying the materials used in this research.

\section{ORCID}

Vanesa Ortega-López: 0000-0003-0212-355x

Víctor Revilla-Cuesta: 0000-0003-3337-6250

Akinmusuru, J. O. (1991). Potential beneficial uses of steel slag wastes for civil engineering purposes. Resources,

Arribas, I., Vegas, I., San-José, J. T. and Manso, J. M. (2014). Durability studies on steelmaking slag concretes. Materials and Design, 63, 168-176. doi: 10.1016/j.matdes.2014.06.002

EUROSLAG. (2018). The European Slag Association. Position Paper on the Status of Ferrous Slag. https://www.euroslag.com/products/statistics/statistics-2018/.

Faleschini, F., Brunelli, K., Zanini, M. A., Dabalà, M. and Pellegrino, C. (2015). Electric Arc Furnace Slag as Coarse Recycled Aggregate for Concrete Production. Journal of Sustainable Metallurgy, 1-7.

Geiseler, J. (1996). Use of steelworks slag in Europe. Waste Management, 16(1-3), 59-63. doi: 10.1016/S0956053X(96)00070-0

Koros, P. J. (2003). Dusts, Scale, Slags, Sludges. . . Not Wastes, but Sources of Profits. Metallurgical and Materials Transactions B: Process Metallurgy and Materials Processing Science, 34(6), 769-779.

Manso, J. M., Polanco, J. A., Losañez, M. and González, J. J. (2006). Durability of concrete made with EAF slag as aggregate. Cement and Concrete Composites, 28(6), 528-534. doi: 10.1016/j.cemconcomp.2006.02.008

Motz, H. and Geiseler, J. (2001). Products of steel slags an opportunity to save natural resources. Waste Management, 21(3), 285-293. doi: 10.1016/S0956-053X(00)00102-1

Ortega-López, V., Fuente-Alonso, J. A., Santamaría, A., San-José, J. T. and Aragón, Á. (2018). Durability studies on fiber-reinforced EAF slag concrete for pavements. Construction and Building Materials, 163, 471-481. doi: 10.1016/j.conbuildmat.2017.12.121 
Pellegrino, C. and Gaddo, V. (2009). Mechanical and durability characteristics of concrete containing EAF slag as aggregate. Cement and Concrete Composites, 31(9), 663-671. doi: 10.1016/j.cemconcomp.2009.05.006

Qasrawi, H. (2014). The use of steel slag aggregate to enhance the mechanical properties of recycled aggregate concrete and retain the environment. Construction and Building Materials, 54, 298-304. doi: 10.1016/j.conbuildmat.2013.12.063

Santamaría, A., Ortega-López, V., Skaf, M., Marcos, I., San-José, J.-T. and González, J. J. (2017). Performance of Hydraulic Mixes Manufactured with Electric Arc Furnace Slag Aggregates. In M. A. Meyers, et al (Ed.), Proceedings of the 3rd Pan American Materials Congress (pp. 227-234). Cham: Springer International Publishing.

Yearbook. (2019). Steel Statistical Yearbook: World Steel Association.
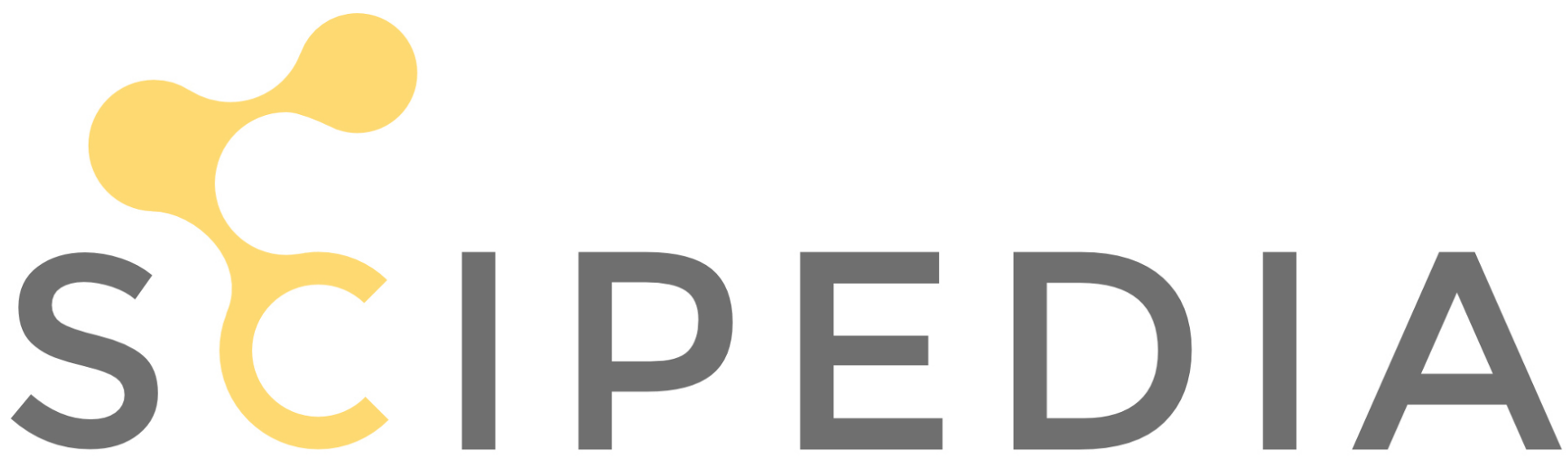

Register for free at https//www.scipedia.com to download the version without the watermark 